\title{
DIGITAL TRANSFORMATION AS EVOLUTION OF THE ORGANIZATIONAL COMMUNICATION MANAGEMENT IN THE TELECOMMUNICATIONS INDUSTRY
}

\author{
Lorian-Ovidiu VINTIL $\breve{A}^{a^{*}}$, Dan POPESCU ${ }^{b}$, Alina-Nicoleta BÎRSAN ${ }^{c}$ \\ a,b, cBucharest University of Economic Studies, Romania
}

DOI: $10.24818 / \mathrm{IMC} / 2020 / 01.17$

\begin{abstract}
We are facing increasing concerns of organizational management teams on expanding their information technology resources that have a major impact on innovating legacy communication services. This way data management flows' optimization is being aimed at; conclusive results being expected to be seen through a communication-based fine-tuning of management's five functions.

The purpose of our research is to identify solutions to fine-tune organizational communication in the current landscape of Telecom Industry practices. Thus, taking into consideration, as experience has managed to show us, that the communication process has become subordinated to Artificial Intelligence, one can see that it continues to validate the approach adopted towards its fine-tuning within large and very large organizations. Since the beginning of 2020, multinationals have been increasingly talking about fine-tuning organizational communication, though scientific input as to how this could be re-addressed are trial based only, while methods and technical means are put to test on a daily basis The majority of successful managers, with rich organizational experience, would like to see a rapid and successful transformation, free of unforeseen consequences for the smooth unfolding of their production. Since the onset of SARS.COV-2 pandemic to date, no mind-blowing solutions, able to accommodate artificial intelligence, information and communication technology (IT\&C) under the umbrella of departmental or organization-wide management have been found. And there is this paradox of what seemed to be rather unlikely before is now the reality: increasingly more organizations are bringing back their employees to workplaces, or at least are offering this alternative. This is the context in which organizational and particularly internal communication play a critical role, in close connection with Human Resources, in planning and distributing back-to-work policies and procedures to employees. So, we make this attempt to propose potential solutions able to render, through fine-tuning organizational communication, Telecom Industry activities more efficient and more effective, without leaving sight of the new dynamic transformations (particularly digital) imposed by the SARS.COV-2 pandemic, in a time of events that, beyond any doubt, have a strong and surprisingly decisive impact on our lives.
\end{abstract}

KEYWORDS: Digital Transformation, Organizational Communication, Telecom Industry, Artificial Intelligence, Hybrid Services, Strategic Management

Motto: "Almost every problem, every conflict, every mistake, or every misunderstanding is, in its core, a communication problem."

\section{INTRODUCTION}

(Alessandra \& Hunsaker, 2008)

Digital transformation (DT) as evolution is imperative for all businesses, from the small and medium enterprises (SMEs) to the multinational companies. It is crystal clear that DT is more than just a concept, as today's experience has proven that no company is able to secure their competitiveness unless they manage to successfully transform and dynamically evolve in the digital era. Paradoxically, many business leaders are still not clear about what DT actually means, and take it as a purely theoretical, content devoid, and only seemingly appealing concept. To the contrary, this is so much the more evident as, while increasingly more business men and women reportedly agree

${ }^{*}$ Corresponding author. E-mail address: lorian.vintila@yahoo.com 
with DT, they have but a limited understanding of the specific steps their organizations need to take to succeed in turning what many call the "Industrial Revolution 4.0" into Evolution.

The questions asked about the alternative of designing new jobs able to foster DT deployment $v$ employing technical advice does not succeed in coming up with answers that quit being appealing to being realistic. And let us not forget that some leaders already think about DT as an obsolete term, and far too broad and/or ambiguous to be of any use. Just as it is still quite difficult to identify what of, and how the current business should be changed and, above all, if the efforts are really worthwhile.

In the end, whether we like it or not, life goes on, and we are forced to rethink the old MOs, to experiment more and more, and to become more resilient to the new context brought along by the coronavirus pandemic crisis, responding not only to customers, but also to competition with empathy, professionalism and honesty. Technology plays a critical part in the ability of any organization to evolve with the market, and to keep increasing the value offered to all beneficiaries of their business.

\section{LITERATURE REVIEW}

Experience has shown us that the complex communication process has become subordinated to Artificial Intelligence (Natale, 2020), and validates the approach adopted to its fine-tuning in large and very large organizations. In this regard, according to Gartner Research (2020), projects falling within the scope of "new organizational communication" are expected to aggregate, value wise, around USD 16 billion by 2030 on the human and artificial intelligence platforms. The human factor manifestly plays a critical part, added to the potential of technology. What we are sure, though, about is that resistance to the change of paradigm shall be bundled with many shortcomings. Thus, not only that people will experience, to a greater or lesser degree, this deep change in the way we communicate, but the new concept will transform not only the telecommunication industry (TI) organizations, but also those acting in other industries, with a positive shift in the way employees perform. In our opinion, the essential aspects related to finetuning organizational communication consist in (Figure no. 1):

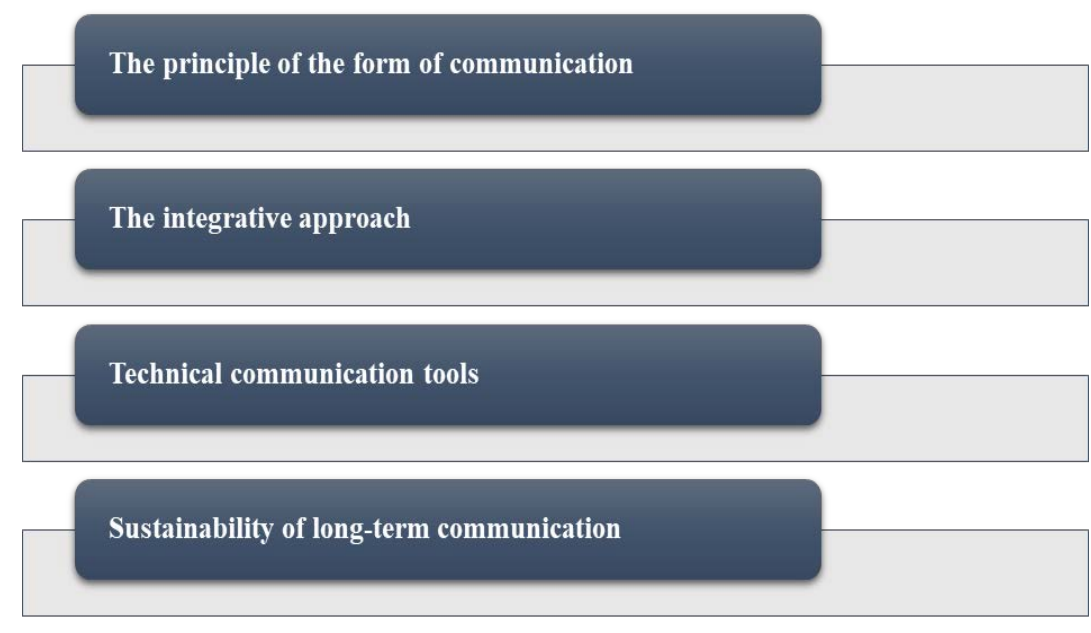

\section{Figure 1. Aspects related to fine-tuning organizational communication}

Source: developed by the authors

Worldwide, it is estimated that the symbiosis between the human factor and artificial intelligence, with a powerful support from communication, will recover 6.2 billion hours of work, representing the 2021 productivity (Gartner Research, 2020). While the statistical data does point to the role of technology investments as a platform for computer and software-assisted communication, not all 
top managers are willing to step over certain "red lines" in connection with long-term investment or other considerations that are more comfort related, and not about digesting and/or committing to the concept of evolution (Oakland \& Tanner, 2007). In this particular context, the experts of Gartner Research (2020) estimate that, by $2020,81 \%$ of the world's top managers have failed to understand either the information, or the infrastructure which accommodates and supports interpretation of the relevant data (Figure no. 2).

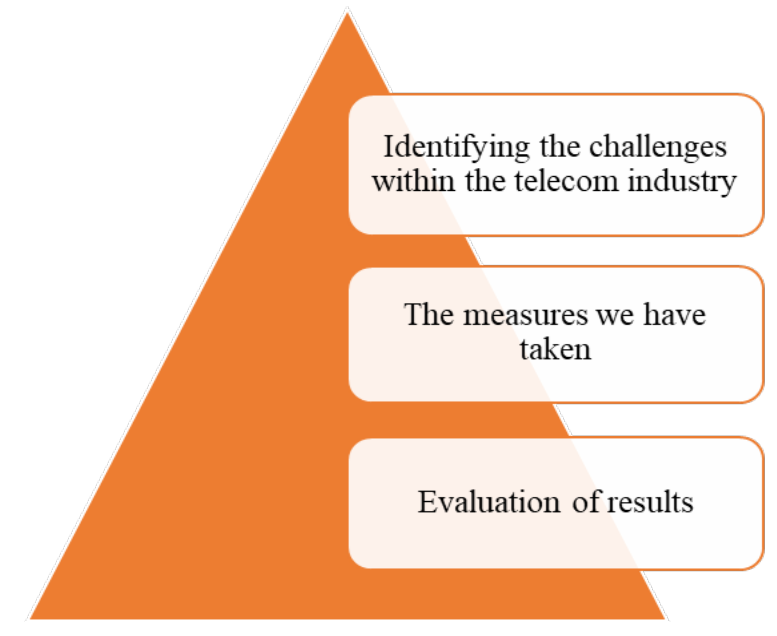

Figure 2. Building the organizational communication strategy

Source: Gartner Research, 2020

In 2014, Beshtawi ${ }^{1}$ and Jaaron were emphasizing that any organizational change in TI not only that will be very slow and difficult, but it will be equally doubtful in terms of success, as it is expected to encounter strong opposition from giants, supporters of the classical management system, which has been rendered obsolete by new methods, techniques and strategies (Beshtawi \& Jaaron, 2014; Kunze et al., 2013; Kotter \& Schilesinger, 2008 etc.). The two experts are known to be change enthusiasts when it comes to both organizational communication (OC) and management per se. In this regard, they embrace strategic management (SM), where essential role of the manager is to advance and support a streamlined adjustment to the new market conditions and requirements.

Having reviewed what is happening today on the Telecomm Market (TM), and in anticipation of the big events of 2020-2024, we can rely on sufficient arguments to lobby for an adaptive management style, so much the more than the market proves highly dynamic, most customers are volatile and, as such, in order to secure market share, any operator is compelled to take out the "big guns" of managerial, strategic or crisis resources. And, even considering that organizational management (OM) should be on the top of the pyramid, we believe that IT tends to amplify the role and importance of SM. Drawing an analogy between the telecom operators and the producers of industrial technology, we can propose the following table that captures the thinking of Fischer and Newig (2016) and Farla et al. (2012) about "the importance of each player in each type of management" (Table 1):

Table 1. Importance of each "player" in each type of management"

\begin{tabular}{|c|c|c|c|c|}
\hline \multirow{2}{*}{ Description } & \multicolumn{3}{|c|}{ Breakdown of each type of management by "player" } \\
\cline { 2 - 5 } & Organizational & Strategic & Tactical & Operational \\
\hline Telecom operator & $70 \%$ & $80 \%$ & $60 \%$ & $85 \%$ \\
\hline Equipment manufacturer & $30 \%$ & $20 \%$ & $40 \%$ & $15 \%$ \\
\hline
\end{tabular}

Source: authors, based on ZTE - Romania internal data 
Hiatt and Creasey (2012) think that Organizational Communication Management (CMO) features a set of practical tools and methods employed in change management (CM), with employee and his responsibilities in focus, so as to help the shift from old ideas and concepts to the current market mindset. The same two authors further underline that $\mathrm{CM}$, in particular OC, provides knowledge to both focus groups and employees dealing with their individual tasks so that they can take part in change, embrace and actively and dynamically support it, never leaving the overall goals and/or organizational objectives out of sight (Hiatt \& Creasey, 2012). As to the role of OC in companies, the experts highlight that this is not about a process to generate business solutions, but about generating predictable human reactions, considering that the most effective strategies adopted to successfully cope with the impact of unpredictable factors on envisaged markets (Lee et al., 2003). Therefore, OM embraces the best-fit managerial type in order to adapt to the market, operational mechanisms being influenced not necessarily by the strategies adopted by the TM players, but by the grass-root conditions of an increasingly fluctuating and unpredictable market.

\section{CASE STUDY ON ZTE. DISCUSSIONS}

For two decades, the gameplay changes for the star players on the TM were brought about by a number of fundamental elements, such as, for instance:

A) Market share (2000 vs 2010 and 2010 vs 2020 - Table 2, Figure 3, and respectively Table 3 and Figure 4):

Table 2. Market share of mobile operators during 2000-2010

\begin{tabular}{|c|c|c|c|c|c|c|c|c|}
\hline & \multicolumn{7}{|c|}{ Continental market share during $2000-2010$} & \multirow{2}{*}{ Globally \% } \\
\cline { 2 - 9 } & Producer & Origin & Europe & N America & S America & Asia & Africa & \\
\hline 1 & Ericsson & Sweden & 54 & 11 & 8 & 8 & 11 & 15.3 \\
\hline 2 & Nokia & Finland & 16 & 10 & 11 & 3 & 14 & 9.0 \\
\hline 3 & Motorola & US & 7 & 38 & 21 & 4 & 13 & 13.8 \\
\hline 4 & Nortel & US & 4 & 23 & 9 & 2 & 7 & 7.5 \\
\hline 5 & Alcatel & France & 9 & 8 & 19 & 5 & 20 & 10.2 \\
\hline 6 & Huawei & China & 4 & 3 & 14 & 31 & 14 & 11.0 \\
\hline 7 & ZTE & China & 2 & 4 & 16 & 37 & 16 & 12.5 \\
\hline 8 & Samsung & Korea & 0 & 0 & 0 & 8 & 5 & 2.2 \\
\hline 9 & Other & Globally & 4 & 3 & 2 & 2 & 0 & 1.8 \\
\hline
\end{tabular}

Source: authors, based on ZTE - Romania internal data

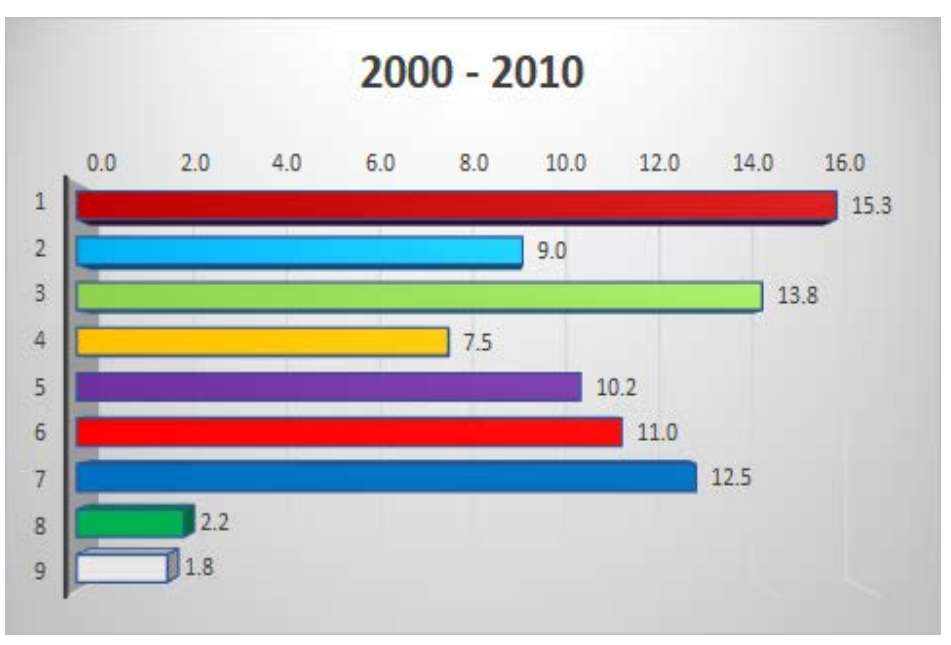

Figure 3. Histogram: Market share of mobile operators during 2000-2010

Source: authors, based on ZTE - Romania internal data 
Table 3. Market share of mobile operators during 2000-2010

\begin{tabular}{|c|c|c|c|c|c|c|c|c|}
\hline & \multicolumn{7}{|c|}{ Continental market share during $2010-2020$} & \multirow{2}{*}{ Global \% } \\
\cline { 2 - 9 } & Producer & Origin & Europe & N America & S America & Asia & Africa & \\
\hline 1 & Ericsson & Sweden & 6 & 31 & 4 & 2 & 3 & 7.7 \\
\hline 2 & Nokia & Finland & 4 & 5 & 2 & 1 & 2 & 2.3 \\
\hline 3 & Motorola & US & 0 & 15 & 1 & 1 & 1 & 3.0 \\
\hline 4 & Nortel & US & 0 & 11 & 1 & 1 & 1 & 2.3 \\
\hline 5 & Alcatel & France & 1 & 14 & 4 & 7 & 17 & 7.2 \\
\hline 6 & Huawei & China & 75 & 9 & 66 & 45 & 56 & 41.8 \\
\hline 7 & ZTE & China & 12 & 7 & 21 & 37 & 18 & 15.8 \\
\hline 8 & Samsung & Korea & 0 & 1 & 0 & 5 & 1 & 1.2 \\
\hline 9 & Other & Globally & 2 & 7 & 1 & 1 & 1 & 2.0 \\
\hline
\end{tabular}

Source: authors, based on ZTE - Romania internal data

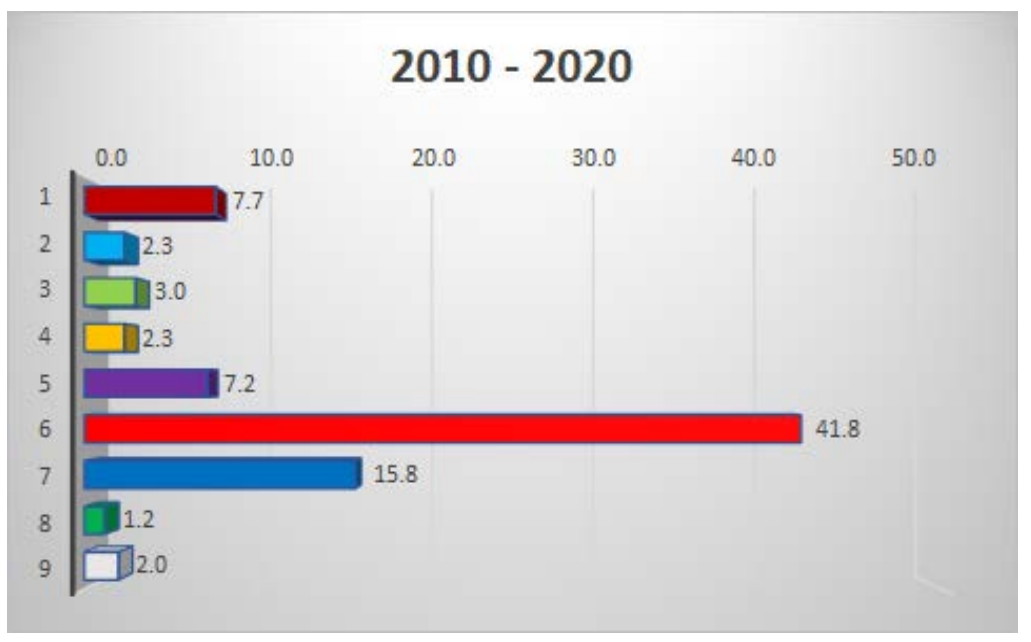

Figure 4. Histogram: Market share of mobile operators during 2000-2010

Source: authors, based on ZTE - Romania internal data

Beyond any doubt, these figures are impressive even for industry outsiders, but they mirror the underlying concepts of a world-class production line. What it should be noted though, besides the change in the planetary hegemony, is how incredibly fast the two Chinese producers (Huawei and ZTE) have managed, in only one decade's time, to overturn a ranking gentrified in the concepts, philosophies and models of the Western companies.

Sharing the views of the TI representatives, we also agree to the fact that the Chinese organizational superiority has won the battle for the supremacy on the market in telecom equipment.

In the same train of thought, we would like to produce some evidence from the Chinese company ZTE, which evidence shows an exceptional platform for communication between members, as well as with external partners. In this context, it is hardly surprising the place of Chinese producers in the world ranking, considering that they were the first to develop the most complex OC system on a platform designed by the researchers of a research and development institute (RDI) based Shenzen, a system that was customized by international teams. 
B) Trade policies (from advance payment to grace period)

In early 2020, the global TM landscape can be summarized as follows (Table 4):

Table 4. Global penetration rate in telecommunication industry

\begin{tabular}{|c|c|c|c|c|c|}
\hline \multirow{2}{*}{ Time period } & \multicolumn{5}{|c|}{ Global penetration rate } \\
\cline { 2 - 6 } & $\begin{array}{c}\text { Fixed } \\
\text { phones }\end{array}$ & Mobile phones & Fixed Internet & Mobile Internet & Cable TV \\
\hline $1990-2000$ & $14 \%$ & $12 \%$ & $1 \%$ & 0 & $1 \%$ \\
\hline $2000-2010$ & $23 \%$ & $38 \%$ & $9 \%$ & $3 \%$ & $42 \%$ \\
\hline $2010-2020$ & $31 \%$ & $104 \%$ & $33 \%$ & $62 \%$ & $58 \%$ \\
\hline
\end{tabular}

Source: Areppim A.G.

Value wise, the difference between time periods is huge, but it finds an explanation in the efforts employed by equipment producers, and less by operators planning to prioritize customer retention before organic growth.

The need for communication has been and still remains constantly progressive, just as both sides (operators and producers) have quickly understood consume-oriented trend of the population, and have acted through rather creative means to penetrate the markets.

For instance, 1997 alone saw a positive balance of 100 thousand mobile subscribers, which points to two conclusions:

1. mis-projected sales;

2. the huge appetite of Romanians for mobile phones and, implicitly, for more efficient communication.

TM has become increasingly more mature and eager for value-added services (mobile Internet, mobile TV, banking apps, 4G coverage and, more recently, 5G, etc.), and this appetite must be satisfied with a developed, secure, and fast telecom network. In terms of the development pace, equipment manufacturers have overtaken telecom operators, and the ferocious appetite for business has shifted to the production line portfolio, with manufacturers incurring operating costs and granting operators grace period and payment terms that could not been even imagined a decade ago. We cannot overlook the excellent performance of the manufacturers from the People's Republic of China which anticipated the moment, prepared diligently for it, and have eventually managed to become the toughest competitors in this industry of inventions, innovations and equipment for fixed, mobile, terrestrial, maritime and satellite telecom operators.

The general finding is shown in the tables and charts above, where we see the Chinese producers holding a majority share of $57.6 \%$ on the global market.

C) Technical strategy (from "plug \& play" products, to detailed customization)

Just as the majority of products are developed without anyone caring about what the end user wants, the same applies also in TI. The year of 2010, just before the global financial crisis, saw teams of experts succeeding, for the very first time in this industry, in developing products in a close cooperation with the end user (in particular the operators of telecommunication services). The chaotic delivery of products to the market, with rivers of financial resources flowing into a desert of conferences and roundtables, was replaced by expert meetings, with team-based technical thinking generating spectacular breakthroughs in technological efficiency. This is a telling sign of the manner in which the shift of paradigm has been brought, for more than 10 years already, value in both technical terms, but also, most importantly, in the budgets of TI players.

\section{D) From direct and indirect maintenance to AI-based maintenance}

We have become used to see that, when a piece of equipment no longer meets their technical datasheet, they are given a diagnostic, and then is either repaired, or replaced. These steps require significant human, technical, logistical and time resources. Having looked again into the procedure 
for response to technical alerts, the TI management teams decided to put in place the artificial intelligence system that examines, diagnoses, repairs and, at the same time, suggests solutions based on well-founded scenarios.

\section{CONCLUSIONS}

The scientific objectives we have set for ourselves are represented by the driving, response and uncontrollable, for a number of reasons, factors. All these factors are represented by humans and computers (IT\&C). If we are to look at how certain components evolve, leaving aside the TC profits, it needs to be said that, further to the shift of influence from the technology centers from North America and Europe to those of Asia (in particular of China), we see more power and desire for $\mathrm{OC}$, more opening towards business and, also, a fine-tuning of the management elements in the executives' portfolio. In absence of this shift of paradigm, it is beyond any doubt that managers could have not successfully represented TI.

The in-scope analysis was also driven by the need to explore solutions to fine-tune OC, together with the TI practices. In this context, we built on the assumption that $\mathrm{OC}$ has two major prevailing characteristics:

a) OC development is directly connected to management processes;

b) harmonization of the development requirements entails: highly skilled human resources, technology and corporate differentiation

In our endeavor, we highlighted the potential to render more efficient individual and collective performance indicators by putting in place and in operation specific ways of virtual organization. Having studied the behavior of managers right after the pandemic went global, we reached the conclusion that the topic of our research explores various manners of creating, managing and also operating TI companies.

The research's main assumption is streamlining work environment with additional resources. On an ever-changing TM, the key challenge is the ability to keep performance controlled and transparent in a business environment with variable and complex sources, translated into state-of-the-art technology.

For instance, communication within multinationals follows a new axis, being that of hybrid services stemming from the technological and digital transformation of equipment and solutions providers. The majority of COOs have now the new task of aligning suppliers on a common business platform so that they can provide technical solutions that go beyond the complexity of the phenomenon (production times, lead-times, installation and commissioning times, and last but not least, times to respond to post-installation interventions).

The current challenge comes from integration of the "multisourcing" services since this requires alignment of the new operations with corporate governance principles in order to mitigate any impact of the security processes and policies that could affect the smooth pursuit of business. It goes without saying that OC in TI is accomplished with the aid of technology, and security breaches can be exploited by third parties.

More precisely, the platforms that integrate these new services are prevailingly intended to managing both external and internal suppliers (company's organizational subdivisions) by aligning demand with solution delivery, all ultimately leading to a more efficient intra- and interdepartmental cooperation, fostering innovation and efficiency of communication processes that are meaningful even for production processes, while keeping data secured.

The TI practice subtly, but unequivocally shows that of all the four types of management, the functional accessory that cannot miss from the portfolio of any manager is the adaptive type. However, in our opinion, beyond these four types of management, we also see a management of process platform transformation that falls under the expertise of the TI players. 


\section{REFERENCES}

Alessandra, T. \& Hunsaker, P.L. (2008). The New art of Managing People, Updated and Revised: Person-to-Person Skills, Guidelines, and Techniques Every Manager Needs to Guide, Direct, and Motivate the Team. New York: Free Press. ISBN: 978-1416550624

Beshtawi, M., Jaaron, A. (2014). Change Management in Telecommunication Sector: a Managerial Framework, Review of Contemporary Business Research, 3(1):127-141. ISSN (online): 23336420. Doi:10.15640/rcbr

Farla et al. (2012). Sustainability transitions in the making: A closer look at actors, strategies and resources, Technological Forecasting and Social Change, 79(6):991-998. Doi:10.1016/j.techfore.2012. 02.001

Fischer, L.B. \& Newig, J. (2016). Importance of Actors and Agency in Sustainability Transistions: A Systematic Exploration of the Literature, Sustainability, 8(5)/476:1-21.

Doi:10.3390/su8050476

Gartner Research (2020). Organizational Communication During the COVID-19 Outbreak. ID: G0 0723251. Analyst: Asia HR Research Team

Hiatt, J. \& Creasey, T. (2012). Change Management: The People Side of Change. Fort Collins, CO: Prosci Learning Center Publications. ISBN: 978-1930885615

Kunze, F., Bohm, S.A., \& Bruch, H. (2013). Age, resistance to change, and job performance: Testing for a common stereotype, Journal of Managerial Psychology, 28(7/8):741-760. Doi: 10.5465/ambpp. 2010.54495229

Kotter, J.P., Schilesinger, L.A. (2008). Choosing Strategies for Change, Harvard Business Review, 57 (21):106-114. Doi:10.1007/978-1-349-20317-8_21

Lee, K., Ashcraft, B., \& Allen, B.J. (2003). The Racial Foundation of Organizational Communication, Communication Theory, 13(1):5-38. Doi: 10.1111 / j.14682885.2003.tb00280.x

Natale, S. (2020). Communicating THROUGH or Communicating WITH: Approaching Artificial Intelligence from a Communication and Media Studies Perspective, Communication Theory, 9:1-6. Doi:10.1093/ct/qtaa022

Oakland, J.S. \& Tanner, S. (2007). Successful Change Management, Total Quality Management \& Business Excellence, 18(1-2):1-19. Doi:10.1080/14783360601042890 